\title{
AC 2008-368: INTERACTIVE LEARNING IN ENGINEERING EDUCATION
}

Jean-Claude Thomassian, State University of New York, Maritime College

Dr. Jean-Claude Thomassian received his BS degrees in Electrical Engineering and Mechanical Engineering from the University of Toledo in 1992 and 1993, respectively, and MS and Ph.D. degrees in Electrical Engineering from The University of Toledo in 1995 and 2002. His main professional interests are in mixed mode IC design and electrical engineering education; his recent research activity concentrates on symbolic analysis of circuits and MOS models.

\section{Anoop Desai, Georgia Southern University}

Dr. Anoop Desai received his BS degree in Production Engineering from the University of Bombay in 1999, and MS and Ph.D. degrees in Industrial Engineering from The University of Cincinnati in 2002 and 2006. His main research interests are in Product Lifecycle Management, Design for the Environment, Total Quality Management including tools for Six Sigma and Ergonomics.

\section{Patrick kinnicutt, Central Michigan University}

Dr. Patrick Kinnicutt received his SB and SM degrees in Civil and Environmental Engineering from the Massachusetts Institute of Technology in 1989 and 1991, respectively. He received his $\mathrm{PhD}$ in Information Technology in Civil Engineering from the Massachusetts Institute of Technology in 1995. Dr. Kinnicutt is currently an Assistant Professor of Science Informatics at Central Michigan University, where he holds a joint appointment in the Geology and Computer Science Departments. His areas of research include spatial modeling and visualization, applications of non-Euclidean distance metrics in geotatistical modeling, applied image processing. 


\title{
Interactive Learning in Engineering Education
}

\begin{abstract}
Incorporating active/cooperative learning into traditional instruction can be a useful pedagogical tool to help students collectively work on a project inside and outside of class time. They can also be held responsible to finish the work if they don't show enough interest to complete the tasks. The learner-centered pedagogy of incorporating projects into formal instruction is assessed and some observations pertaining to this experience are cited. To achieve this goal, a design project is chosen at the beginning of the course in order to motivate and verify/go over course content and to make students work in teams. The experience will be measured by student's responses to a survey and their ability to complete a wide variety of tasks related to the subject matter.
\end{abstract}

\section{Introduction}

We decided to introduce Active/Cooperative Learning techniques in engineering education to engage and motivate students in the learning process inside and outside of class time. To achieve this goal, design projects designed to make students work in teams are assigned during the course of the semester. Active learning techniques are not new [1-7]. On the other hand, its support for teaching at the university level has been a hot topic of research in recent years [8-19]. According to Bonwell and Eison, Active Learning is described as follows: "When using active learning students are engaged in more activities than just listening. They are involved in dialog, debate, writing, and problem solving, as well as higher-order thinking, e.g., analysis, synthesis, evaluation." [4].

According to Johnson, Johnson, and Smith, Cooperative Learning is described as follows: "Is an instructional paradigm in which teams of students work on structured tasks (e.g., homework assignments, laboratory experiments, or design projects) under conditions that meet five criteria: positive interdependence, individual accountability, face-to-face interaction, appropriate use of collaborative skills, and regular self-assessment of team functioning. Many studies have shown that when correctly implemented, cooperative learning improves information acquisition and retention, higher-level thinking skills, interpersonal and communication skills, and selfconfidence." [6].

Regardless of the subject matter, research has shown that active/cooperative learning is an effective teaching technique compared to using traditional instruction alone such as lectures. By using Active/Cooperative Learning techniques students seem to, 1) learn more material, 2) remember the information longer, 3) enjoy the subject matter more, 4) establish peer relationship and 5) have near perfect attendance. So, instead of the students learning on their own, now, students learn in the classroom with the help of the instructor and other students; outside of the classroom they must work together in groups and individually be held accountable for completion of the tasks. 
Active/Cooperative Learning methods were used on four different State University campuses in the US and one University in China. A list of some courses that used Active Learning to enhance teaching are listed as follows: Digital Design, Control Systems, Network Analysis, Circuit Analysis, Electronics, Circuits Lab, Interfacing Programmable Devices, Digital Design Lab, Computing for Engineers - Matlab/Java, Intro to Computer Engineering, Engineering Graphics, and Engineering Economy. The experiences by both faculty and students have been positive.

\section{Traditional Instruction vs. Active/Cooperative Learning}

This section shows how traditional instruction differs from active/cooperative learning. As shown in Fig. 1, in traditional instruction the instructor has structured lecture notes. Students passively receive information from the instructor.

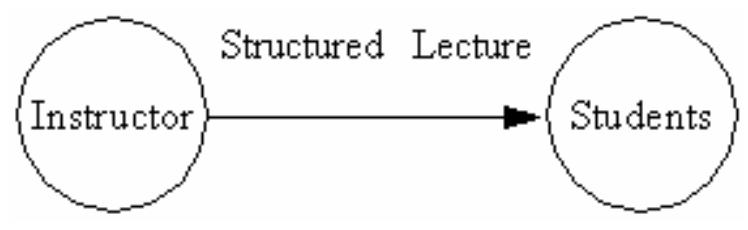

Fig.1 Traditional Instruction

In Fig. 2, in the Active/Cooperative Learning method, the instructor receives feedback to adjust lectures to be more instrumental to the projects and to address where the students were having difficulty. Students are engaged in the learning process, they are required to do activities inside and outside of class time.

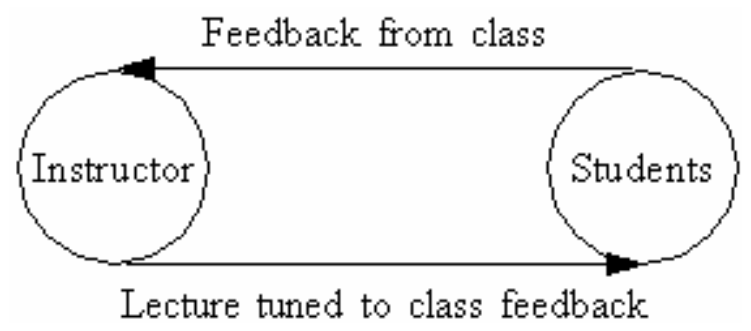

Fig. 2 Active/Cooperative Learning Method

\section{Active/Cooperative Learning into Your Classroom}

Incorporating Active/Cooperative Learning methods in the classroom can be challenging to both faculty and students who are not used to this technique of instruction. The faculty gives up some control of the class by becoming a facilitator. The students are required to act and take more responsibility on how and what they learn.

Faculty including active/cooperative learning takes extra time to prepare for class than a traditional lecture course. The amount of extra time required depends on how many changes are adopted. Faculty members can start with small changes and then increase their use of active/cooperative learning. Typically it takes a few extra hours per week of extra preparation time 
compared to regular lectures. The time needed to prepare will diminish by experience and each time the course is offered.

Some of the experiences and activities that were used to enhance active/cooperative learning:

- Transforming the class into groups of 3-5 students per group or more depending on class size from the get go.

- Building of the community to allow students to be more open and trusting of each other.

- Having each group make small 3-5 minutes presentations each class from previously covered material

- Assigning group assignments that use computer tools such as Pspice, Matlab, Java, etc.

- Assigning mini guided projects for groups to work inside and outside of class time.

- Interactive mini tutorials especially geared for introductory classes.

- Media Based Tutorials that allows student to learn at their own pace and time.

- Brainstorming to involve the whole class in a discussion by introducing a problem.

Some remarks on the above mentioned experiences and activities

A group of typically four students is assigned by the instructor either by random or some other criteria from the start of the exercise, ensuring that the students understand the purpose of the groups, assigning them tasks connected to a course objective and making them accountable. Students need a clear justification for creating and using groups. This is done to help our students better learn the material and function in teams.

One of the key things to do is spend time setting the stage and building a sense of community in the class. Students need to be more open and trusting of each other. They need to learn what makes a successful group and what good and bad group behavior is. They also need to spend time to get to know each other.

Each class period one or two groups, time permitting, goes up to the board and makes a 3-5 minute maximum presentation. This can be anything that was covered from the previous lectures or something related to the new material to be covered. Mini short presentations usually work very well since it reinforces the material covered in the lectures and if there are any difficulties or deficiencies, the instructor or students can give feedback instantly. It also teaches the students to function in teams and forces them to act.

Assigning group computer assignments and projects forces the student to learn new tools and holds them responsible for achieving the desired outcome. The thing to make sure to do here is designing the assignments and projects so that it can be partitioned within the group. The group members are also individually accountable for their understanding of the solution and their participation.

Some students enrolled in introductory courses such as Intro to Engineering, Circuits and Electronics have never used software tools such as Mathematica or PSpice. Interactive mini tutorials especially geared towards such introductory courses expedite the student to master the tools and motivates them to learn some basic concepts. 
Media Based Tutorials where all the main points and steps are explained in detail. Students can go through the tutorial at their own pace and in their own time. There is no rush or time constraints to go through the tutorials [20]. These tutorials can be housed on WebCT or the course web site for students to access.

Brainstorming can be used to involve the whole class in a discussion by introducing a new concept or problem. This requires getting the students involved in thinking about and discussing a new concept in a class setting, so that the students try to develop solutions to problems using their problem solving skills. There can be a question and answer session where the instructor asks various students pointed questions, to force student participation and engage the students in the problem solving process. This can be motivated by assigning extra credit for student participation.

The authors encouraged and conducted brain storming sessions in an engineering education classroom setting. The typical questions asked involved questions regarding basic engineering concepts. The questions sought to determine the level of understanding among members of the brainstorming group with a view to encourage active/cooperative learning among participants. It has been noticed that active communication wherein students engage in verbally expressing opinions in an informal setting results in a much faster pace of learning. It has also been shown that this sequence of events makes the learning process much more exciting and interesting.

Research has shown that injecting a couple pauses during lecture time enhances learning and the effectiveness of lectures [21-23].

By design, the method did not incorporate features that are costly or require unusual classroom resources like computers or tables designed for work groups. Any faculty at any University can implement active learning.

\section{Effectiveness of Active/Cooperative Learning vs. Lectures: Course Survey Result}

In this section the result of a survey question is shown. The students were asked to fill out a survey usually two weeks before the end of the course in the academic years from 2006 to 2007. The survey included the following question below which also had some space left below the question to allow students to provide some feedback. Since most other courses in the students program use a traditional lecture style, it is easy for them to compare the styles.

Do you feel that Active/Cooperative Learning improved your understanding compared to a traditional lecture format? Why or why not? The scale is designated as 5 for strongly agree (SA), 4 agree(A), 3 for no opinion (NO), 2 for disagree (D), and 1 for strongly disagree (SD).

Table 1 below details the evaluation responses for the past two academic years. Followed by some feedback regarding the student's responses to the survey question. 
Table 1: Student Survey Respondents

\begin{tabular}{|l|c|c|}
\hline & 2006 & 2007 \\
\hline Class Enrollment & 67 & 71 \\
\hline Number of Respondents & 56 & 63 \\
\hline Response Percentage & $84 \%$ & $88 \%$ \\
\hline
\end{tabular}

The students responded very positively to this question, with $89 \%$ of respondents responding "strongly agree" or "agree" in 2006 and 91\% of respondents responding "strongly agree" or "agree" in 2007, as shown in Fig. 3. The Students liked the discussions and the question and answer studio format. They seemed to appreciate the chance for interaction with the instructor and their peers. Keeping a journal of what worked and what did not work in the course will help improve the experience next time a course is offered.
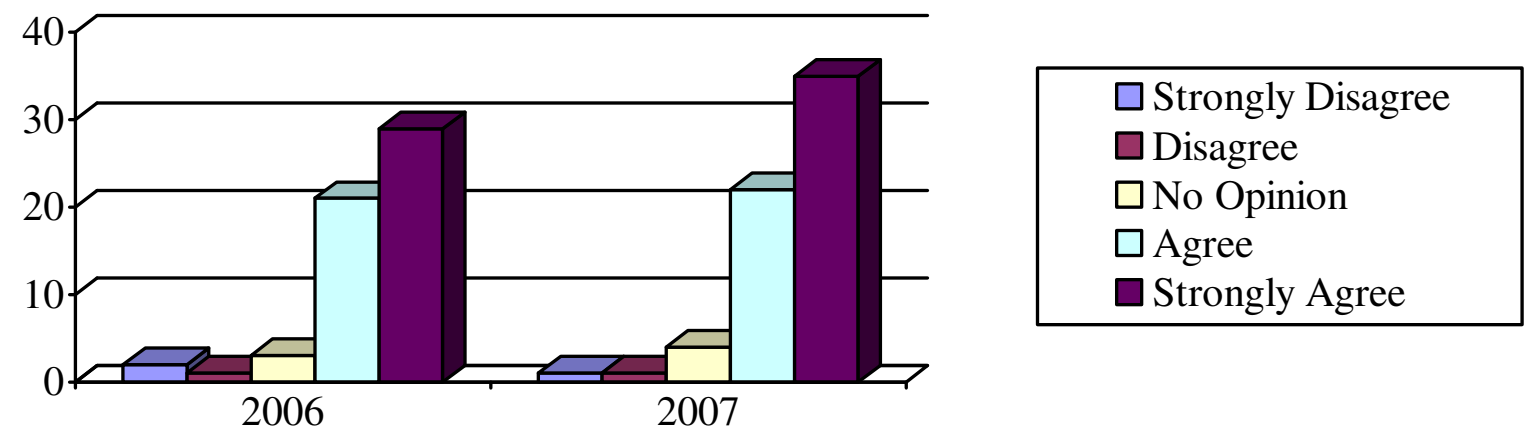

Fig.3 Response to "Do you feel that Active/Cooperative Learning improved your understanding compared to a traditional lecture format?"

\section{Conclusion}

In summary, there is significant evidence collected by researchers in engineering education and learning that traditional instructional methods, lecture and problem solving, are not effective in prompting conceptual learning in engineering education. There is enough agreement among researchers that the engineering teaching community would do well to use curricula and methods based on practices that have actually been demonstrated to increase student learning. These active/cooperative learning activities have been used successfully in numerous cases in fields such as physics, chemistry, geology, biology and the other sciences. It is useful to examine in a scientific way the learning results of these new methods in specific learning contexts. Initial results show that active/cooperative learning, computer based, and interactive learning environments effectively serve the diversity of students studying engineering.

\section{Bibliography}

1. Sweller, J., and Cooper, G. A., The use of worked examples as a substitute for problem solving in learning algebra. Cognition and Instruction, 2(1), 59-89, 1985.

2. Chickering, A., and Gamson, Z., Seven Principles for Good Practice, AAHE Bulletin, 39, 3-7, 1987.

3. Sweller, J., Cognitive technology: Some procedures for facilitating learning and problem solving in mathematics and science, Journal of Educational Psychology, 81 (4), 457-466, 1989. 
4. Bonwell, C. C., and Eison, J. A., Active Learning: Creating Excitement in the Classroom, ASHE-ERIC Higher Education Report No. 1, Washington, DC, Jossey-Bass, 1991.

5. Johnson, D. W., and Johnson, R. T., Cooperation and competition: Theory and research, Interaction Book Company, Edina, MN, 1989.

6. Johnson, D. W., Johnson, R., and Smith, K., Active Learning: Cooperation in the College Classroom, Interaction Book Company, Edina, MN, 1991.

7. Silberman, M., Active Learning: 101 Stategies to Teach Any Subject, Allyn and Bacon, Boston, MA, 1996.

8. Nagurney, L.S., Teaching introductory programming for engineers in an interactive classroom, $31^{\text {st }}$ ASEE/IEEE Frontiers in Education Conference, Oct. 2001.

9. Hall, S.R., Waitz, I., Brodeur, D.R., Soderholm, D.H., and Nasr, R., Adoption of active learning in a lecturebased engineering class, $32^{\text {nd }}$ ASEE/IEEE Frontiers in Education, Oct. 2002.

10. Lincke, S.J., Creating interest in operating systems via active learning, $35^{\text {th }}$ ASEE/IEEE Frontiers in Education Conference, Oct. 2005.

11. Hulls, C.C.W., Neale, A.J., Komalo, B.N., Petrov, V. and Brush, D.J., Interactive online tutorial assistance for a first programming course, IEEE Transactions on Education, Vol. 48, Issue 4, pp. 719 - 728, Nov. 2005.

12. Masters, J., Madhyastha, T.M., Shakouri, A., Educational Applets for active learning in properties of electronic materials, IEEE Transactions on Education, Vol. 48, Issue 1, pp. 29 - 36, Feb 2005

13. Diesel, E., Alley, M., Schreiber, M., Borrego, M, Improving Student Learning in Large Classes by Incorporating Active Learning with a New Design of Teaching Slides, $36^{\text {th }}$ ASEE/IEEE Frontiers in Education Conference, Oct. 2006.

14. Pantic, M., Zwitserloot, R., de Weerdt, M., Work in Progress: Learner-Centered Online Learning Facility, $36^{\text {th }}$ ASEE/IEEE Frontiers in Education Conference, Oct. 2006.

15. Pantic, M., Zwitserloot, Active Learning of Introductory Machine Learning, $36^{\text {th }}$ ASEE/IEEE Frontiers in Education Conference, Oct. 2006.

16. Mason, D. S., Students remember what they do, Journal of Chemical Education, vol. 83, Issue 4, pp. 521, 2006

17. Juedes, D., Fleeman, D., Marling, C., \& Chelberg, D., Work in progress - Anytime, anywhere active learning in computer science, $37^{\text {th }}$ ASEE/IEEE Frontiers in Education Conference, Oct. 2007.

18. Everett, L., Pennathur, A., Jones, V., Kephart, K., \& Villa, E., Workshop - creating learning opportunities: Building active learning problems to create conceptual conflict for enduring understanding, $37^{\text {th }}$ ASEE/IEEE Frontiers in Education Conference, Oct. 2007.

19. Hauck, S., Active Learning Techniques in a CAD Course, IEEE International Conference on Microelectronic Systems Education, pp. 125 - 126, 2007.

20. Thomassian, J.-C., Kumazawa, R. and Kinnicutt, P., A Study of Freshmen Students' Outlook to Media Based Tutorials of MATLAB/JAVA in Computing for Engineers, Proceedings, 2007 ASEE Annual Conference and Exposition, June 24-27, 2007.

21. Hartley, J., and Davies, I., "Note Taking: A Critical Review," Programmed Learning and Educational Technology, Vol. 15, 1978, pp. 207-224.

22. Di Vesta, F., and D. Smith, "The Pausing Principle: Increasing the Efficiency of Memory for Ongoing Events," Contemporary EducationalPsychology, Vol. 4, 1979.

23. Ruhl, K., Hughes, C. and Schloss, P., "Using the Pause Procedure to Enhance Lecture Recall," Teacher Education and Special Education, Vol. 10, Winter 1987, pp. 14-18.

\section{Appendix}

The appendix includes excerpts from group assignments/projects used in the Active/Cooperative Learning model for an Electronics course.

Use the circuit from part 2 in class to display the I-V characteristics of the following four diodes available in Pspice Library. Add the D1N914, D1N750, and D1N4148 diodes in parallel with the existing D1N4002. Make sure they are all facing the same direction. Since they are in parallel they will all have the same voltage. Run the simulation again and this time display all four diode current on the $y$-axis of the graph. Reset the y-axis range to go from $-10 \mathrm{~mA}$ to $30 \mathrm{~mA}$. Turn in your schematic and the display of all four diode characteristics. 
Simulation of Zener Diodes: A breakout diode, DbreakZ, exists to model zener diodes in Pspice. The approximate zener breakdown voltage is set with the parameter BV. Thus, to simulate a zener diode with a zener voltage of approximately 10 volts, add the parameter $B V=10$ to the breakout model. Note that the resistance of the diode will cause the zener voltage to be slightly different in the simulation. Perform the DC Sweep analysis as described in class. Sweep the input voltage source from -14 to 5 volts in increments of 0.1 volts. After simulating, modify the $\mathrm{y}$-axis to display currents from $-50 \mathrm{~mA}$ to $50 \mathrm{~mA}$.

Turn in your schematic and the display of zener diode characteristic.

Design the circuit shown below to have a Q-point of $I_{C Q}=1 \mathrm{~mA}$ and $V_{\mathrm{CEQ}}=10 \mathrm{~V}$. Make the circuit $\beta$ independent. Show the steps of your design procedure and state your assumptions. Use Pspice to simulate your design. Turn in a copy of the schematic and the portion of the Pspice output file that shows the operating point. What is the percent error in the collector current? Leave the circuit the same but change the $\beta$ in the simulation to 400 and re-run the simulation. Turn in a print out of the new operating point. By what percentage did the collector current change for this change in $\beta$ ?

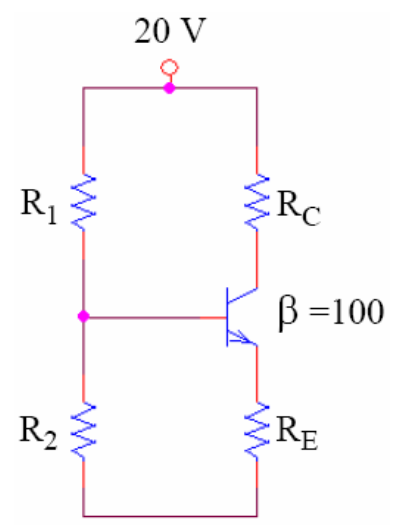

